\title{
Species-specific isotope dilution analysis of monomethylmercury in sediment using GC/ICP-ToF-MS and comparison with ICP-Q-MS and ICP-SF-MS
}

\author{
Sebastian Faßbender ${ }^{1}$ (D) Marcus von der $\mathrm{Au}^{1}$ (D) $\cdot$ Maren Koenig ${ }^{1} \cdot$ Jürgen Pelzer $^{2} \cdot$ Christian Piechotta $^{3}$. \\ Jochen Vogl ${ }^{1}$ (i) $\cdot$ Björn Meermann ${ }^{1}$ (D)
}

Received: 8 April 2021 / Revised: 28 May 2021 / Accepted: 22 June 2021 / Published online: 23 July 2021

(C) The Author(s) 2021

\begin{abstract}
A recently introduced inductively coupled plasma-time-of-flight-mass spectrometer (ICP-ToF-MS) shows enhanced sensitivity compared to previous developments and superior isotope ratio precision compared to other ToF and commonly used singlecollector ICP-MS instruments. Following this fact, an improvement for isotope dilution ICP-MS using the new instrumentation has been reported. This study aimed at investigating whether this improvement also meets the requirements of species-specific isotope dilution using GC/ICP-MS, where short transient signals are recorded. The results of the analysis of monomethylmercury (MMHg) of a sediment reference material show that isotope ratio precision of ICP-MS instruments equipped with quadrupole, sector-field, and time-of-flight mass analyzers is similar within a broad range of peak signal-to-noise ratio when analyzing one isotopic system. The procedural limit of quantification (LOQ) for MMHg, expressed as mass fraction of Hg being present as $\mathrm{MMHg}, w(\mathrm{Hg})_{\mathrm{MMHg}}$, was similar as well for all investigated instruments and ranged between 0.003 and $0.016 \mu \mathrm{g} / \mathrm{kg}$. Due to the simultaneous detection capability, the ICP-ToF-MS might, however, be more favorable when several isotopic systems are analyzed within one measurement. In a case study, the GC/ICP-ToF-MS coupling was applied for analysis of MMHg in sediments of Finow Canal, a historic German canal heavily polluted with mercury. Mass fractions between 0.180 and 41 $\mu \mathrm{g} / \mathrm{kg}\left(w(\mathrm{Hg})_{\mathrm{MMHg}}\right)$ for $\mathrm{MMHg}$, and 0.056 and $126 \mathrm{mg} / \mathrm{kg}\left(w(\mathrm{Hg})_{\text {total }}\right)$ for total mercury were found in sediment samples taken from the canal upstream and downstream of a former chemical plant.
\end{abstract}

Keywords Mercury speciation · GC/ICP-ToF-MS · Legacy pollution $\cdot$ Finow Canal $\cdot$ Environmental analysis

\section{Introduction}

Species-specific isotope dilution (SSID) analysis is a primary method producing most reliable and precise results $[1,2]$. Isotope ratio precision is the crucial factor associated with the measuring instrument contributing to the measurement

Björn Meermann

bjoern.meermann@bam.de

1 Division 1.1 - Inorganic Trace Analysis, Federal Institute for Materials Research and Testing (BAM), Richard-Willstätter-Str. 11, 12489 Berlin, Germany

2 Gembitzer Str. 23, 13053 Berlin, Germany

3 Division 1.8 - Environmental Analysis, Federal Institute for Materials Research and Testing (BAM), Richard-Willstätter-Str. 11, 12489 Berlin, Germany uncertainty in SSID analyses, and improvements in isotope ratio precision could translate into higher precision of the results. The latest generation of inductively coupled plasmatime-of-flight-mass spectrometers (ICP-ToF-MS) was shown to exhibit largely improved precision and consistency of isotope ratios over a wide concentration range, as well as improved sensitivity as compared to earlier ICP-ToF-MS systems [3]. Since ICP-ToF-MS instruments work with a quasisimultaneous detection of all $\mathrm{m} / \mathrm{z}$ ratios, they were also shown to be superior to instruments with sequential mass analyzers, such as quadrupole $(\mathrm{Q})$ and single-collector magnetic sectorfield (SF) ICP-MS instruments, regarding isotope ratio precision $[4,5]$. However, these comparisons have only been conducted with standard continuous liquid introduction analyses and are not readily transferable to the measurement of isotope ratios in (short) transient signals, as it is the case for hyphenations of ICP-MS with separation techniques, such as GC, 
HPLC, IC, or CE. This is due to poorer statistics resulting from the short time available for the isotope ratio measurement and small analyte quantity [6].

These hyphenations of ICP-MS, especially using HPLC and GC, have substantial advantages in analyzing (trace) elemental species, including high sensitivity and selectivity $[7$, 8]. Moreover, depending on the matrix, complex sample preparation procedures are necessary and may lead to losses of analyte or species transformation [9], problems that can best be overcome with SSID approaches facilitated by the isotopespecific detection capability of ICP-MS [10]. Studies applying SSID for HPLC/ and GC/ICP-MS analyses have been conducted mostly for speciation of $\mathrm{Hg}$ [11-15], $\mathrm{Pb}$ [14], S [16], and $\mathrm{Sn}[13,14,17]$. In terms of isotope ratio precision, studies applying GC/ICP-ToF-MS for species-specific isotopic analysis have reached relative standard deviations $\left(s_{\text {rel }}\right)$ of $0.2-$ $0.5 \%$ using high analyte concentrations $[18,19]$. For quantification with SSID, a good precision also for low concentrations, i.e., small peaks, is mandatory.

An area of broad interest is $\mathrm{Hg}$ speciation because of its complex biogeochemical cycle [20], including natural methylation processes producing extremely toxic monomethylmercury (MMHg), especially in the aquatic environment. Sediments and soils can act as sinks for inorganic $\mathrm{Hg}$ species, while they are simultaneously sources of volatile $\left(\mathrm{Hg}^{0}\right)$ and organic species, such as MMHg [20-22], although the amount of substance fraction of MMHg in total $\mathrm{Hg}$ is suggested to be as low as $0.1-1 \%[20,23]$. Natural background levels of $\mathrm{Hg}$ in soils and sediments are thought to be in the order of $0.1 \mathrm{mg} / \mathrm{kg}[20,22]$, corresponding to natural MMHg mass fractions between 0.1 and $1 \mu \mathrm{g} / \mathrm{kg}$. Due to its lipophilicity and strong affinity to thiol groups present in biomolecules containing the amino acid cysteine [24]. MMHg has a high potential for bioaccumulation and biomagnification. This is highlighted by exceptionally high MMHg concentrations found in fish and fish predators [20] as well as aquatic insects [25] and birds [26] living in close vicinity to Hg-contaminated waterbodies. In addition to that, MMHg ingested mainly by consumption of predatory fish and rice can also pass the blood-brain barrier in humans [20].

One example of a highly $\mathrm{Hg}$-contaminated waterbody is Finow Canal, the oldest artificial waterway still in operation in Germany, with $\mathrm{Hg}$ mass fractions of up to or higher than $100 \mathrm{mg} / \mathrm{kg}$ in the sediment [27, 28], which has been attributed to a chemical plant producing (among others) mercury-based seed dressings [28, 29]. Despite this high mass fraction of $\mathrm{Hg}$, anaerobic conditions, and high amounts of organic matter and iron [28], which are all favorable for Hg methylation [20,30], no investigations of $\mathrm{Hg}$ speciation have been conducted there up to now.

In this study, we evaluate the performance of a recently commercialized ICP-ToF-MS in SSID GC/ICP-MS and compare it with widely used ICP-Q-MS and ICP-SF-MS instruments. The practicability of the ICP-ToF-MS is shown by a case study conducting mercury speciation analysis in sediments of Finow Canal on length from before the known polluted sited into the confluence with Oder-Havel Canal.

\section{Materials and methods}

\section{Samples}

Samples were taken from eight locations following the Finow Canal (Brandenburg, Germany) downstream from the crossing of Finow Canal and Oder-Havel Canal near Marienwerder to the confluence of both canals near the town Niederfinow (Fig. 1). Two additional samples were taken from Alte Oder River, ca. 8 and $16 \mathrm{~km}$ downstream of Niederfinow, in Oderberg and Hohensaaten, respectively. Sample W was the only non-sediment sample. It was taken from the uppermost centimeters of the soil of a washing bed next to Finow Canal, where sediment removed from the canal bed within the city of Eberswalde has been deposited periodically up to the 1980s [29]. This material was sampled with a stainless-steel shovel after removing the plants covering the soil surface. The sediment samples were taken from piers extending up to $2 \mathrm{~m}$ into the canal with a Van Veen grab sampler. At each location, the grab sampler was used several times, so that up to $2 \mathrm{~L}$ of sediment material was collected and filled into a glass jar. However, at sites 5 and 8 , the sediment layer was much thinner and considerably less amount of sample material was collected. More details on the sampling sites can be found in Table S1 of the Supplementary Information (ESM).

The samples were freeze-dried and sieved to a particle size below $250 \mu \mathrm{m}$ before analysis. Freeze-drying is a gentle preservation method which was shown to have no significant influence on $\mathrm{Hg}$ speciation [31]. In between sampling, freezedrying, sieving, and analysis, the samples were stored refrigerated at $4{ }^{\circ} \mathrm{C}$. For correction of the residual moisture content, the dry matter fraction of each sample and the reference materials was determined in triplicate according to DIN EN 15934 [32].

\section{Reagents}

Ultrapure water (resistivity $\geq 18.2 \mathrm{M} \Omega \mathrm{cm}$ ) was obtained from a Milli-Q Reference water purification system (Merck Millipore, Darmstadt, Germany). Concentrated nitric acid $\left(\mathrm{HNO}_{3}\right)$ and hydrochloric acid ( $\left.\mathrm{HCl}\right)$ (both p.a. quality from Th. Geyer, Renningen, Germany) were further purified by a two-stage sub-boiling distillation (PicoTrace, Bovenden, Germany). Copper sulfate $\left(\mathrm{CuSO}_{4}\right)$ pentahydrate (p.a.), glacial acetic acid (p.a.), methanol (for residue analysis), and sodium hydroxide solution $(\mathrm{NaOH}, 32 \%$, p.a.) were also purchased from Th. Geyer. Methylmercury chloride (99.8\%), 


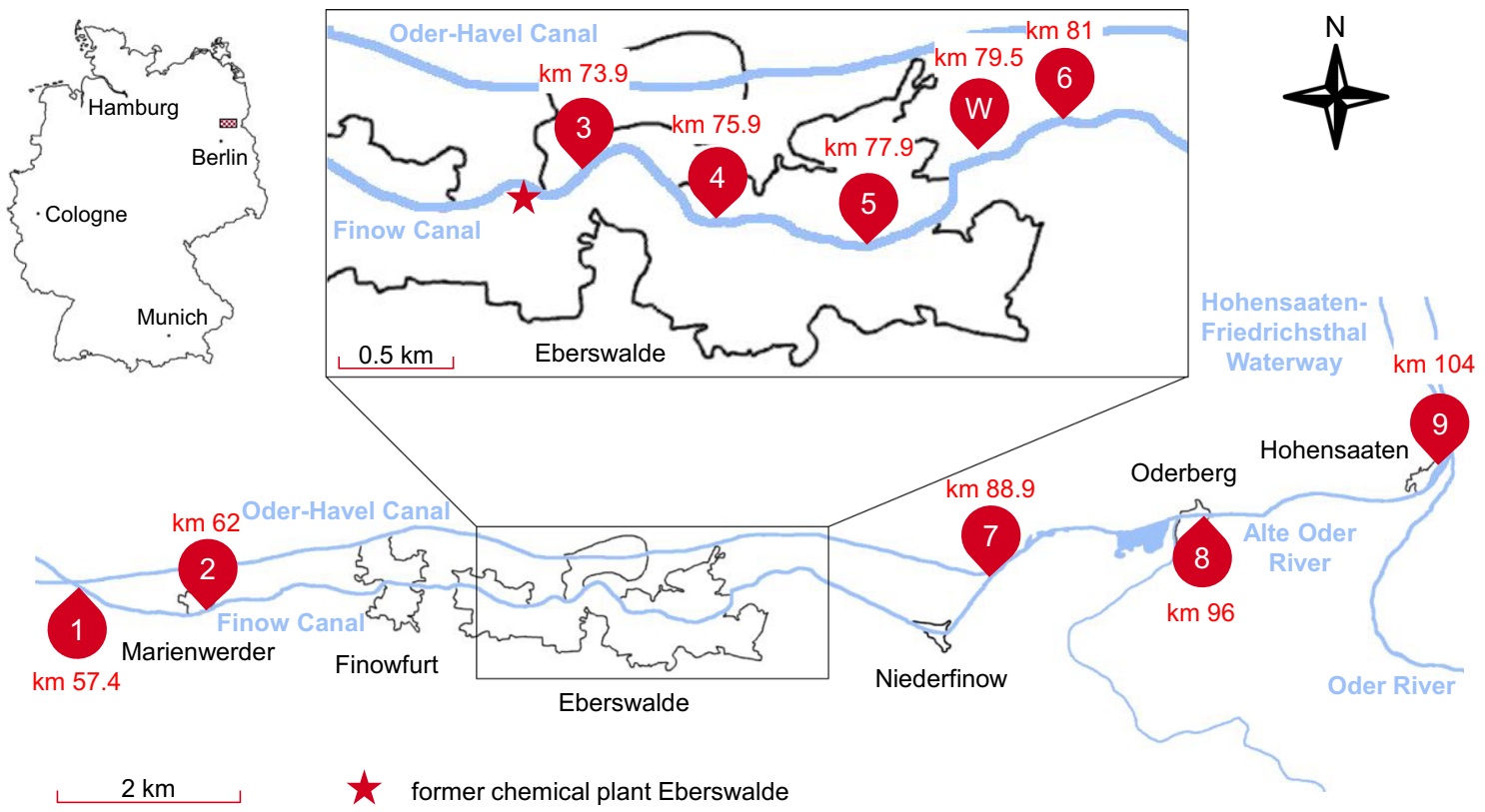

Fig. 1 Map of the sampling area at Finow Canal in Brandenburg, Germany, north-east of Berlin with labeling of all sampling sites

ethylmercury chloride (technical), tetrahydrofuran (THF, stabilizer-free), hydrofluoric acid (HF, 48\%, ultrapure), and sodium sulfate (p.a., anhydrous) were purchased from SigmaAldrich (Taufkirchen, Germany). The derivatization agent sodium tetra-n-propylborate $\left(\mathrm{NaBPr}_{4},>98.0 \%\right)$, n-hexane, and dichloromethane (DCM) (both picograde, for residue analysis) were obtained from LGC Standards (Wesel, Germany). Sodium thiosulfate pentahydrate (p.a.) was purchased from Merck (Darmstadt, Germany).

${ }^{201} \mathrm{Hg}$-enriched mercury oxide $(\mathrm{HgO})$ was purchased from Chemotrade (Düsseldorf, Germany) and ${ }^{201} \mathrm{Hg}$-enriched monomethylmercury solution $(w(\mathrm{MMHg})=5.1 \mathrm{mg} / \mathrm{kg}$ in $3: 1$ acetic acid/methanol mixture) from ISC Science (Oviedo, Spain). Dilutions of $6.9 \mu \mathrm{g} / \mathrm{kg}$ and $0.068 \mu \mathrm{g} / \mathrm{kg}$ ${ }^{201} \mathrm{Hg}$-enriched $\mathrm{MMHg}$ in methanol with dilute $\mathrm{HCl}(w \approx$ $0.02 \mathrm{~kg} / \mathrm{kg}$ ) were prepared gravimetrically for spiking the samples. The ${ }^{201} \mathrm{Hg}$-enriched $\mathrm{HgO}$ was dissolved in dilute $\mathrm{HNO}_{3}$ and diluted further with ultrapure water to a $\mathrm{HNO}_{3}$ concentration of $1 \mathrm{~mol} / \mathrm{L}$. This stock solution was diluted with $\mathrm{HNO}_{3}(c=1 \mathrm{~mol} / \mathrm{L})$ to a mass fraction of $20.7 \mathrm{mg} / \mathrm{kg} \mathrm{Hg}$, which was determined by reverse-ID ICP-MS prior to this study. A second dilution of $1.1 \mathrm{mg} / \mathrm{kg}$ in $\mathrm{HNO}_{3}(c=1$ $\mathrm{mol} / \mathrm{L}$ ) was prepared gravimetrically.

For validation of the analytical method, the sediment reference materials IAEA-456 (IAEA, Vienna, Austria; 0.125 $\mu \mathrm{g} / \mathrm{kg} \mathrm{MMHg}$ as $\mathrm{Hg}$ and $0.077 \mathrm{mg} / \mathrm{kg}$ total $\mathrm{Hg}$ ), ERMCC020 (BAM, Berlin, Germany; $27.4 \mathrm{mg} / \mathrm{kg}$ total $\mathrm{Hg}$ ), and ERM-CC580 (IRMM, Geel, Belgium; $75.5 \mu \mathrm{g} / \mathrm{kg} \mathrm{MMHg}$ and $132 \mathrm{mg} / \mathrm{kg}$ total $\mathrm{Hg}$ ) were used. Details on the ${ }^{201} \mathrm{Hg}$ enriched spike and reference materials can be found in Table S2 of the ESM.

\section{Mercury speciation analysis}

\section{Extraction}

The extraction procedure was based on a procedure described by Carrasco and Vassileva [33] using an acidic extraction solution of $\mathrm{CuSO}_{4}$ and $\mathrm{HNO}_{3}$ and DCM to directly extract MMHg into the organic phase for separation of inorganic $\mathrm{Hg}$. The required volume of spike solution was added to the sample with the extraction solution and estimated for every sample to target an ${ }^{201} \mathrm{Hg} /{ }^{202} \mathrm{Hg}$ ratio of approximately 1 . The actual amount of spike solution added was determined gravimetrically. A $\mathrm{Na}_{2} \mathrm{~S}_{2} \mathrm{O}_{3}$ solution was used to back extract $\mathrm{MMHg}$ into the aqueous phase for propylation, and hexane was used for extraction of the propylated $\mathrm{Hg}$ species. A detailed description of the sample preparation procedure can be found in section S1 of the ESM.

Very low concentrated sediment samples (IAEA-456 and samples 1 and 8 ) were prepared with a sample amount of $1 \mathrm{~g}$; of all other samples, an amount of $0.25 \mathrm{~g}$ was used. Procedural blanks were prepared by following the whole sample preparation procedure without sediment and with (for determination of LOQ) and without ${ }^{201} \mathrm{Hg}$-enriched MMHg spike. Three replicates were prepared for each sample and reference material per day, with exception of IAEA-456, which was prepared in three replicates on 1 day and only once on each of three other days due to the limited amount of this material. Each replicate was analyzed three times with GC/ICP-ToF-MS, with exception of the replicates of low concentrated samples (IAEA-456 and samples 1,2, and 8), which were analyzed five times. For measurements with GC/ICP-Q-MS and GC/ 
ICP-SF-MS, two replicates of ERM-CC580 and three procedural blanks with and one procedural blank without ${ }^{201} \mathrm{Hg}$ enriched MMHg spike were prepared. Each replicate of the unspiked blank and the reference material was analyzed three times, and each replicate of the spiked blanks five times.

\section{Analysis}

The analysis of $\mathrm{MMHg}$ was conducted using a Trace 1310 GC (Thermo Fisher Scientific, Bremen, Germany) coupled to an icpTOF 2R (TOFWERK, Thun, Switzerland) via a heated transfer line (Thermo Fisher Scientific, Bremen, Germany) and a dual introduction injector. The straight inlet of the injector was connected to the transfer line, which consists of a sulfinert-coated stainless-steel tubing surrounded with a heating jacket. The GC column was fed into the stainless-steel tubing ensuring that the column end was located in the middle of the heating jacket. An additional gas line was also connected to the transfer line, so that the GC effluent was carried into the plasma within a gas flow of $0.6 \mathrm{~L} / \mathrm{min}$ argon gas leading to rapid transfer and minimized band broadening. The additional gas was guided through a 3-m coiled stainless-steel tubing located inside the GC oven to allow for pre-heating of the gas. The second inlet of the injector was connected via tygon tubing to a $20-\mathrm{mL}$ glass cyclonic spray chamber equipped with a glass concentric nebulizer introducing a constant flow of a $1 \mu \mathrm{g} / \mathrm{L} \mathrm{Tl}$ standard solution in $\mathrm{HNO}_{3}(w \approx 0.01 \mathrm{~kg} / \mathrm{kg})$. This was necessary for two separate reasons. In ICP-MS, instrumental mass fractionation compromises the measured isotope ratio of the sample leading to a bias in results of ID analyses. This mass bias must be corrected for by analyzing a sample with a known isotope ratio (e.g., natural isotopic composition). Due to the drift of plasma conditions, it is preferred to use an internal standard rather than a separate measurement. Because the $\mathrm{MMHg}$ spike is only enriched in ${ }^{201} \mathrm{Hg}$ but not monoisotopic, Tl was used as an internal standard since it is similar in atomic mass and does not lead to spectral interferences with $\mathrm{Hg}$ isotopes. The wet aerosol was also used to introduce oxygen for complete combustion of the organic compounds eluting from the GC column. When working with dry aerosol, incomplete combustion of organic compounds (solvent, analytes) could lead to carbon deposits on the cones of the ICPMS instrument, especially in splitless injection mode. The GC was equipped with a $30 \mathrm{~m}$ TG5-SilMS column (0.25 mm i.d., $0.25 \mu \mathrm{m}$ film thickness; Thermo Fisher Scientific, Bremen, Germany) and a programmable temperature vaporizing injector (PTV) operated in splitless mode with an injection volume of $2 \mu \mathrm{L}$. The injection program used was a heating ramp of $10{ }^{\circ} \mathrm{C} / \mathrm{s}$ from 250 to $400{ }^{\circ} \mathrm{C}$. Further details on operating parameters can be found in Tables S3 and S4 of the ESM.

For coupling of the GC to an ICAP Q ICP-Q-MS and an Element 2 ICP-SF-MS (both from Thermo Fisher Scientific, Bremen, Germany), the same interface and GC parameters were used.

The data acquisition parameters of the ICP-MS instruments, especially the integration (or dwell) time, were optimized to allow for a maximum signal-to-noise ratio $(\mathrm{S} / \mathrm{N})$ and a reasonable number of data points for low $\mathrm{S} / \mathrm{N}$. In general, an increasing integration time results in increasing $\mathrm{S} / \mathrm{N}$ and decreasing number of data points per chromatographic peak. However, for isotope ratio precision, both a high $\mathrm{S} / \mathrm{N}$ and a high number of data points per peak are favorable. It should be noted that the range of mass fractions of $\mathrm{Hg}$ being present as $\mathrm{MMHg}$ $\left(w(\mathrm{Hg})_{\mathrm{MMHg}}\right)$ of the samples and reference materials was very large, between 0.125 and $75.5 \mu \mathrm{g} / \mathrm{kg}$, resulting in very small peaks for low mass fractions and prominent peaks for high mass fractions. Therefore, the acquisition parameters could not be optimized for maximum isotope ratio precision, which is also largely dependent on the concentration/peak height of the analyte. This means that the resulting isotope ratio precision is rather a realistic one than a maximum precision attainable with the respective instrument for transient signals. Based on these considerations and tests with $\mathrm{MMHg}$ of natural isotope ratio, a compromising integration time of $100 \mathrm{~ms}$ per isotope was selected. All other instrumental parameters can be found in Tables S5 and S6 of the ESM.

\section{Data evaluation}

For consistent data treatment, the data from GC/ICP-MS analyses were evaluated using Microsoft Excel 365. With respect to the simultaneous detection, ICP-ToF-MS is similar to multicollector-ICP-MS (MC-ICP-MS), several approaches for calculating precise isotope ratios from transient MC-ICP-MS signals have been described, and linear regression (LRS) and peak area integration (PAI) methods have been found to be best suited [34, 35]. The LRS approach, however, is not suited for low $\mathrm{S} / \mathrm{N}$ because it requires data without baseline correction. Therefore, a baseline-corrected PAI approach of a previous work [36] was adapted for the determination of the isotope ratio of ${ }^{201} \mathrm{Hg} /{ }^{202} \mathrm{Hg}$ of the $\mathrm{MMHg}$ peak. The average baseline intensity and standard deviation $(s)$ were determined from 50 data points each before and after the peak. The average baseline intensity was subtracted from every data point of the peak and peak data points were used for calculation when the intensity was larger than the average baseline intensity plus $3 \times_{s}$. The sum of these data points was used as the intensity of the respective isotope. 
A mass bias correction was performed following the Russell law using a $\mathrm{Tl}$ solution supplied by continuous liquid introduction as shown in Eqs. 1 to 3.

$R_{\mathrm{Tl}, \text { experimental }}=R_{\mathrm{Tl}, \text { true }} \times\left(\frac{m_{203 \mathrm{Tl}}}{m_{205 \mathrm{Tl}}}\right)^{f}$

$f=\frac{\ln \left(\frac{R_{\mathrm{Tl}, \text { experimental }}}{R_{\mathrm{Tl}, \text { true }}}\right)}{\ln \left(\frac{m_{203 \mathrm{Tl}}}{m_{205 \mathrm{Tl}}}\right)}$

The experimental ${ }^{203} \mathrm{Tl} /{ }^{205} \mathrm{Tl}$ isotope ratio $\left(R_{\mathrm{Tl} \text {,experimental }}\right)$ was determined by averaging the isotope ratio of every data point within the peak. The isotopic abundances used for calculating the true $\mathrm{Tl}$ isotope ratio $\left(R_{\mathrm{Tl}, \text { true }}\right)$ and isotopic masses of $\mathrm{Tl}\left(m_{203 \mathrm{Tl}}, m_{205 \mathrm{Tl}}\right)$ were taken from the Commission on Isotopic Abundances and Atomic Weights (CIAAW)
[37-39]. The mass bias factor $(f)$ was then applied on the experimental ${ }^{201} \mathrm{Hg} /{ }^{202} \mathrm{Hg}$ isotope ratio $\left(R_{\mathrm{Hg} \text {,experimental }}\right)$ :

$R_{\mathrm{Hg}, \text { corr }}=\frac{R_{\mathrm{Hg}, \text { experimental }}}{\left(\frac{m_{201 \mathrm{Hg}}}{m_{202 \mathrm{Hg}}}\right)^{f}}$

The applicability of this procedure was checked by analyzing the ${ }^{201} \mathrm{Hg} /{ }^{202} \mathrm{Hg}$ ratio of unspiked samples, and the mean corrected ${ }^{201} \mathrm{Hg} /{ }^{202} \mathrm{Hg}\left(R_{\mathrm{Hg}, \text { corr }}\right)$ was within the uncertainty range of the natural isotope ratio. The mass bias corrected $\mathrm{Hg}$ isotope ratios $\left(R_{\mathrm{Hg}, \text { corr }}\right)$ of repeated measurements of one sample replicate were averaged and subsequently used for calculation of the mass fraction of $\mathrm{Hg}$ being present as $\mathrm{MMHg}$ $\left(w(\mathrm{Hg})_{\mathrm{MMHg}, \text { sample }}\right)$ of the replicate as shown in Eq. 4. All sample results were corrected for the dry matter fraction $(D M)$.

$w(\mathrm{Hg})_{\mathrm{MMHg}, \text { sample }}=\frac{M_{\mathrm{Hg}} \times m_{\text {spike }} \times w(\mathrm{MMHg})_{\text {spike }} \times\left(R_{\mathrm{Hg}, \text { corr }} \times A_{202 \mathrm{Hg}, \text { spike }}-A_{201 \mathrm{Hg}, \text { spike }}\right)}{D M \times m_{\text {sample }} \times M_{\mathrm{MMHg}} \times\left(A_{201 \mathrm{Hg}, \text { natural }}-R_{\mathrm{Hg}, \text { corr }} \times A_{202 \mathrm{Hg}, \text { natural }}\right)}$

The molar mass of the spike $\mathrm{MMHg}\left(M_{\mathrm{MMHg}}\right)$ was calculated from the isotopic masses of $\mathrm{Hg}$ isotopes taken from CIAAW [38] and abundances given by the manufacturer. The molar mass of $\mathrm{Hg}\left(M_{\mathrm{Hg}}\right)$ was taken from CIAAW [38], and the mass fraction of the spike dilution ( $\left.w(\mathrm{MMHg})_{\text {spike }}\right)$ was calculated based on the mass fraction of the stock solution given by the manufacturer and the gravimetric dilution. All masses including the mass of spike dilution added to the sample ( $\left.m_{\text {spike }}\right)$ and the mass of the sample ( $\left.m_{\text {sample }}\right)$ were weighed on an analytical balance (RC201D, Sartorius, Göttingen, Germany). Isotopic abundances of the sample $\left(A_{201 \mathrm{Hg}, \text { natural }}\right.$; $\left.A_{202 \mathrm{Hg} \text {,natural }}\right)$ were taken from CIAAW [39], and isotopic abundances of the spike $\left(A_{201 \mathrm{Hg}, \text { spike }} ; A_{202 \mathrm{Hg} \text {,spike }}\right)$ were taken from the manufacturer's information.

The measurement uncertainty of $w(\mathrm{Hg})_{\mathrm{MMHg}}$ was calculated for each replicate applying the Kragten method [40] for Eq. 4. The standard error of the mean $\left(s_{m}\right)$ of the $\mathrm{Hg}$ isotope ratio and the dry matter fraction were used as the uncertainty components of the respective quantities. For plotting the results, all $w(\mathrm{Hg})_{\mathrm{MMHg}}$ of the replicates of a sample were averaged, and a pooled uncertainty $\left(u_{\text {pooled }}\right)$ was calculated from the uncertainties of the replicates $\left(u_{1}, u_{2}, \ldots, u_{n}\right)$ and the number of replicates $(n)$ as shown in Eq. 5.

$\mathrm{u}_{\text {pooled }}=\sqrt{\frac{\mathrm{u}_{1}{ }^{2}+\mathrm{u}_{2}{ }^{2}+\ldots+\mathrm{u}_{\mathrm{n}}{ }^{2}}{\mathrm{n}}}$

The pooled uncertainty was then combined with the standard error of the mean of the replicates $\left(s_{\mathrm{m}, \text { replicates }}\right)$ to give the final combined uncertainty $\left(u_{\text {combined }}\right)$ of $w(\mathrm{Hg})_{\mathrm{MMHg}}$ as shown in Eq. 6.

$u_{\text {combined }}=\sqrt{u_{\text {pooled }^{2}+s_{\text {m,replicates }}^{2}}}$

The expanded uncertainty $(U)$ with a coverage of approximately $95 \%$ was calculated by multiplying $u_{\text {pooled }}$ with the coverage factor $(k=2)$. As procedure blank samples prepared in parallel to the sediment samples using the whole extraction and derivatization procedure did not show any MMHg peak and spiked procedure blank samples resulted in very low negative mass fractions, a blank correction could be omitted and no cross-contamination was observed.

\section{Total mercury analysis}

\section{Digestion}

For analysis of total $\mathrm{Hg}$ mass fractions, $0.5 \mathrm{~g}$ of sample was weighed into a $35-\mathrm{mL}$ quartz microwave vessel fitted with a PFA liner, and the ${ }^{201} \mathrm{Hg}$-enriched spike solution was added. For digestion, $6 \mathrm{~mL}$ conc. $\mathrm{HNO}_{3}(w \approx 0.65 \mathrm{~kg} / \mathrm{kg}), 2 \mathrm{~mL}$ conc. $\mathrm{HCl}(w \approx 0.31 \mathrm{~kg} / \mathrm{kg})$, and $3 \mathrm{~mL}$ conc. $\mathrm{HF}(w \approx 0.48 \mathrm{~kg} / \mathrm{kg})$ were added. The sample was digested in a CEM Discover SPD microwave (Kamp-Lintfort, Germany) at $200{ }^{\circ} \mathrm{C}$ for 20 min. The supernatant of the resulting digest was taken off and diluted to an average acid concentration of 1-2 mol/L. $\mathrm{Hg}$ was separated from the matrix using disposable PP anion 
exchange columns (DWK Life Sciences, Wertheim, Germany) filled with $1.5 \mathrm{~mL}$ AG1-X8 resin (200-400 mesh, Bio-Rad, Feldkirchen, Germany). The columns were washed with elution reagent $(0.1 \mathrm{~g} / \mathrm{kg} \mathrm{L}$-cysteine in $0.02 \mathrm{~kg} / \mathrm{kg} \mathrm{HNO} 3)$ and $4 \times 5 \mathrm{~mL}$ ultrapure water. Conditioning was done with 3 $\mathrm{mL}$ conc. $\mathrm{HCl}, 5 \mathrm{~mL}$ ultrapure water, and $5 \mathrm{~mL} \mathrm{HNO}_{3}(c=1$ $\mathrm{mol} / \mathrm{L}$ ). Subsequently, the diluted sample digest was loaded onto the column, and the matrix was washed out with $3 \times 5 \mathrm{~mL}$ $\mathrm{HNO}_{3}(c=1 \mathrm{~mol} / \mathrm{L})$ and $5 \mathrm{~mL}$ ultrapure water. $\mathrm{Hg}$ was eluted with $2 \times 5 \mathrm{~mL} \mathrm{~L}$-cysteine $(w=0.1 \mathrm{~g} / \mathrm{kg})$ in $\mathrm{HNO}_{3}(w=0.02$ $\mathrm{kg} / \mathrm{kg}$ ). For analysis, the sample solutions were diluted with $\mathrm{HNO}_{3}(w=0.02 \mathrm{~kg} / \mathrm{kg})$ to give an appropriate signal intensity. This matrix separation procedure was necessary to ensure matrix-matching between the samples and the ICP Hg standard solution used for mass bias correction because instrumental mass fractionation is strongly influenced by the sample matrix.

\section{Analysis}

Total $\mathrm{Hg}$ analysis was conducted on an Element 2 sector-field ICP-MS (Thermo Fisher Scientific, Bremen, Germany) equipped with a self-aspirating glass concentric nebulizer (nominal uptake rate $0.2 \mathrm{~mL} / \mathrm{min}$ ) and a glass cyclonic spray chamber $(20 \mathrm{~mL})$. The instrumental parameters used can be found in Table S7 of the ESM. Three replicates per sample were prepared, and three measurements were conducted for each replicate. For mass bias correction, an ICP Hg standard solution was analyzed for natural ${ }^{201} \mathrm{Hg} /{ }^{202} \mathrm{Hg}$. The background $\mathrm{Hg}$ mass fraction was determined by analyzing three blank samples spiked with ${ }^{201} \mathrm{Hg}$-enriched $\mathrm{Hg}$ solution. The measurement uncertainty was calculated as described in the MMHg section with the background mass fraction as additional component.

\section{Results and discussion}

\section{Validation of the SSID GC/ICP-ToF-MS and ID ICP-MS analytical methods}

The analytical method for the analysis of MMHg was validated by analyzing the reference materials ERM-CC580 and IAEA-456 using the procedures for high and low concentrated samples, respectively. Recovery and repeatability were evaluated by performing analyses of the reference materials on four different days. The repeatability of the isotope ratio of one sample was $0.66 \%$ (pooled $s_{\text {rel }}$ of $m=3$ repeated measurements of each of the $n=12$ sample replicates) for ERMCC580 representing samples with high $w(\mathrm{Hg})_{\mathrm{MMHg}}$ and $4.7 \%$ ( $m=5, n=6$ ) for IAEA-456 representing samples with low $w(\mathrm{Hg})_{\mathrm{MMHg}}$. The repeatability of the sample preparation was $1.8 \%\left(s_{\text {rel }}\right.$ of $\mathrm{n}=12$ sample replicates) for ERM-CC580 and
$4.6 \%(\mathrm{n}=6)$ for IAEA-456. The mean recoveries with their associated expanded uncertainties are $(108 \pm 7) \%(n=12)$ for ERM-CC580 and $(105 \pm 10) \%(n=6)$ for IAEA-456. The analytical method for the analysis of total $\mathrm{Hg}$ was validated by analyzing the reference materials ERM-CC580, ERM$\mathrm{CC} 020$, and IAEA-456 in triplicate. The mean recoveries with their associated expanded uncertainties are $(103 \pm 3) \%$ for ERM-CC $580,(100 \pm 3) \%$ for ERM-CC020, and $(107 \pm 9) \%$ for IAEA-456. The results of all analyses of the reference materials were not significantly different from the certified values as shown by $E_{n}$-values of $<1$, determined according to DIN EN ISO/IEC 17043 [41].

The limits of quantification (LOQ) of the complete analytical procedures were determined by spiking blank samples with the ${ }^{201} \mathrm{Hg}$-enriched spike solutions in triplicate. The LOQ was calculated as $10 \times S$ of the blank replicates and was $0.008 \mu \mathrm{g} / \mathrm{kg}$ (expressed as $w(\mathrm{Hg})_{\mathrm{MMHg}}$ for a sample weight of $1 \mathrm{~g}$ ) in case of MMHg and $0.01 \mathrm{mg} / \mathrm{kg}$ (expressed as $w(\mathrm{Hg})$ total for a sample weight of $0.5 \mathrm{~g}$ ) in case of total $\mathrm{Hg}$. The mass fractions of all samples were above the respective LOQ.

\section{Comparison of time-of-flight-, quadrupole-, and sector-field ICP-MS instruments for SSID GC/ICP-MS}

The performance of GC/ICP-ToF-MS, GC/ICP-Q-MS, and GC/ICP-SF-MS for SSID of MMHg was compared based on the analysis of the ERM-CC580 reference material. The mean recoveries with their associated expanded uncertainties are $(108 \pm 7) \%(n=12)$ determined with GC/ICP-ToF-MS, $(109 \pm 7) \%(n=2)$ with GC/ICP-Q-MS, and $(108 \pm 7) \%(n=$ 2) with GC/ICP-SF-MS. The results clearly demonstrate the equivalence of the three investigated instruments, not only in terms of recovery but also regarding the uncertainty. However, $w(\mathrm{Hg})_{\mathrm{MMHg}}$ is very high in ERM-CC580 resulting in high peaks and easy and precise isotope ratio calculation, regardless of the used instrument. An investigation of the uncertainty budget (Fig. 2) revealed that the combined uncertainty of $w(\mathrm{Hg})_{\mathrm{MMHg}}$ is largely dependent on the uncertainty of the mass fraction of the ${ }^{201} \mathrm{Hg}$-enriched MMHg spike solution and only to a small extent on the uncertainty of the experimental isotope ratio.

For a more thorough investigation in the region of lower concentrations, the hexane extracts of the reference material were diluted by a factor of 10 to 175 with hexane and analyzed again with all three instruments. For this, only one sample replicate was prepared. Quite surprisingly, the results were still similar, with only slightly wider uncertainty ranges for the highest dilution. The precision of the measured ${ }^{201} \mathrm{Hg} /{ }^{202} \mathrm{Hg}$ ratio depends on the $\mathrm{S} / \mathrm{N}$ of the peaks, as shown in Fig. 3, and decreases with decreasing S/N. No significant differences between the three mass analyzers can be observed, and the higher uncertainty of the ToF at S/N 20.5 may be a 
Fig. 2 Relative uncertainty contributions for each input quantity to the combined uncertainty, exemplarily shown for the undiluted ERM-CC580 extract analyzed with GC/ICPToF-MS ( $n=3$ replicates). Sixteen input quantities with separate contributions of $0.5 \%$ or lower are summarized as "Others"

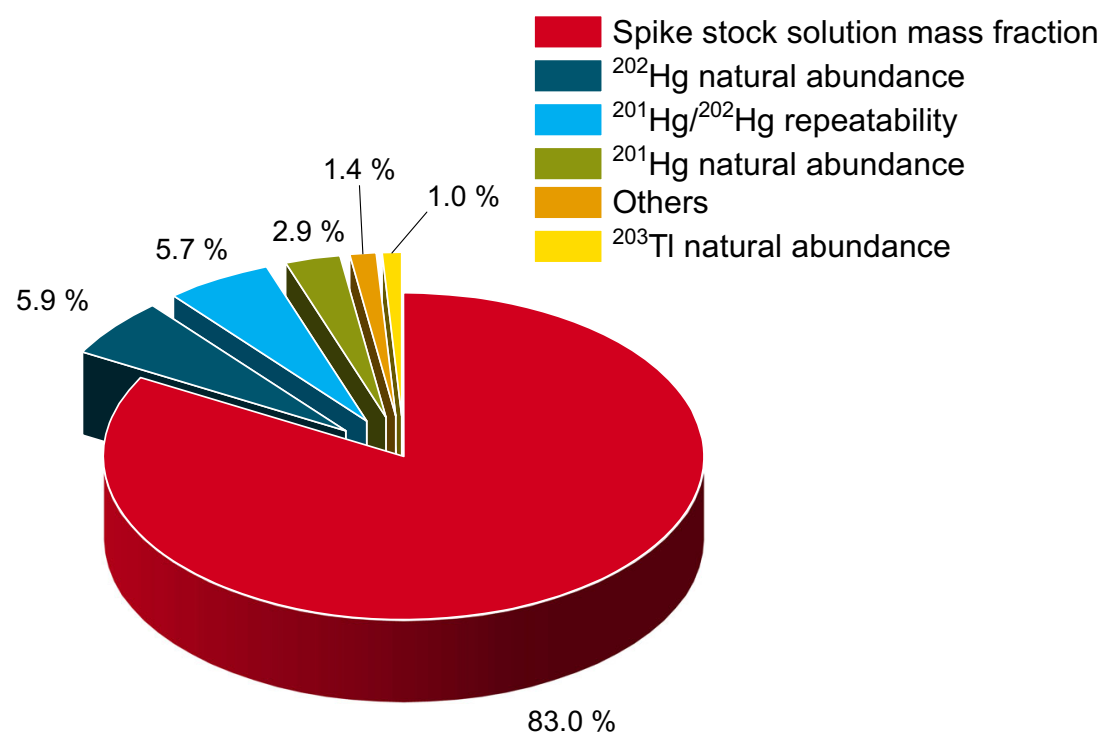

random outlier and cannot be conclusively interpreted without more data.

Assuming an infinite precision of the measured ${ }^{201} \mathrm{Hg} /{ }^{202} \mathrm{Hg}$ ratio (the only uncertainty component depending on the sample), the relative combined uncertainty of the resulting $w(\mathrm{Hg})_{\mathrm{MMHg}}$ is $3 \%$. It becomes clear that above a $\mathrm{S} /$ $\mathrm{N}$ of 10 , the ${ }^{201} \mathrm{Hg} /{ }^{202} \mathrm{Hg}$ ratio precision is below $1.5 \%$, which accounts for less than $25 \%$ of the combined uncertainty of $w(\mathrm{Hg})_{\mathrm{MMHg}}$ or an increase of the combined uncertainty of $1 \%$ (to then $4 \%$ ). Therefore, above $\mathrm{S} / \mathrm{N} 10$, the combined uncertainty is dominated by the uncertainty of the spike mass fraction, and small differences in isotope ratio precision are of

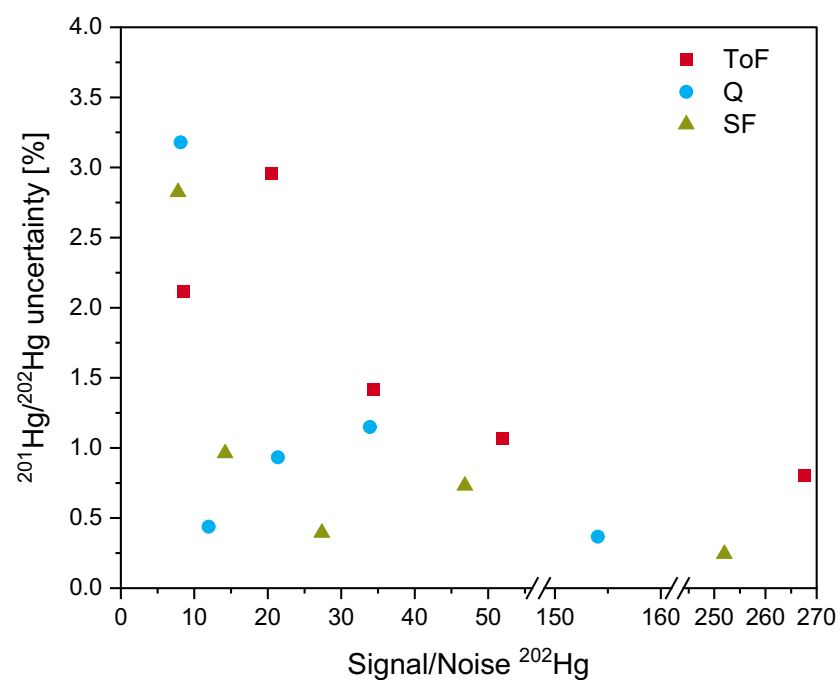

Fig. 3 Relative standard uncertainty $(k=1)$ of ${ }^{201} \mathrm{Hg} /{ }^{202} \mathrm{Hg}$ in relation to the signal-to-noise ratio of the ${ }^{202} \mathrm{Hg}$ peak of a diluted extract of ERMCC580. Dilution factors 1 to 175 , uncertainty based on $m=3$ repeated measurements of each sample with the respective GC/ICP-MS coupling using a ToF, Q, and SF instrument. The signal-to-noise ratio is the average of $m=3$ repeated measurements no consequence. Below S/N 10, the influence of the measured ${ }^{201} \mathrm{Hg}{ }^{202} \mathrm{Hg}$ ratio on the combined uncertainty increases, but this effect is in the same order of magnitude for all three instruments.

The LOQ of the MMHg analysis for all three instruments was determined as described in the previous section. The resulting LOQ were $0.008 \mu \mathrm{g} / \mathrm{kg}, 0.016 \mu \mathrm{g} / \mathrm{kg}$, and 0.003 $\mu \mathrm{g} / \mathrm{kg}$ for ToF, Q, and SF instruments, respectively, calculated for a sample weight of $1 \mathrm{~g}$ and expressed as $w(\mathrm{Hg})_{\mathrm{MMHg}}$. Although there is a spread of factor 5 , the differences are most likely not significant in practice and are more probably due to random effects than to instrumental properties.

These results show that although reported for continuous liquid introduction, ICP-ToF-MS is not significantly superior to sequential Q- or SF-based instruments in terms of isotope ratio precision for SSID in transient signals, when one element is analyzed. The superiority of ICP-ToF-MS in measurements using conventional liquid introduction is apparently not readily transferable to transient signals. This is most probably due to the measurement principle of the ToF mass analyzer, which uses pulsed ion packages from the continuous ion stream generated by the ICP ion source [42]. The dwell time for one ion package resulting in a single mass spectrum is $46 \mu \mathrm{s}$ [43]. Although the detection of ions is (quasi-) simultaneous, the number of ions per ion package is very small, and thereby isotope ratio precision of single spectra is low. By averaging a great number of spectra within a selected integration time, the isotope ratio precision can be increased. However, for the analysis of transient signals, the integration time is limited by the peak width because a certain number of data points per peak (around 20 to 30) is required to maintain an acceptable precision also for small (low and narrow) peaks. Therefore, the superior precision attainable with long integration times of several seconds, as described for continuous introduction [3, 
4], cannot be reached when acquiring narrow and low transient signals. It is expectable that this will be different if more than one isotope system is analyzed because additional analytes do not influence ToF data acquisition since they are already detected (simultaneously) anyway. As opposed to this, with Q and SF mass analyzers, every additional analyte will result in less data points per peak or shorter dwell times, and thus significantly decreasing isotope ratio precision. Thus, the strength of ToF might come to light once multi-isotope systems and short transient signals are investigated.

\section{Mercury speciation analysis of Finow Canal sediment}

The SSID GC/ICP-ToF-MS and ID ICP-SF-MS analysis of the sediment samples from Finow Canal revealed $w(\mathrm{Hg})_{\mathrm{MMHg}}$ between 0.180 and $39 \mu \mathrm{g} / \mathrm{kg}$, and $w(\mathrm{Hg})_{\text {total }}$ of 0.056 to 126 $\mathrm{mg} / \mathrm{kg}$ as shown in Fig. 4. The variation in relative expanded uncertainty (6-14\%) is caused by a varying repeatability of the sample preparation (replicates). Because this was not the case for reference materials, which in contrast to the samples are homogenized by grinding, the varying repeatability might be attributable to sample heterogeneity. However, even a relative expanded uncertainty of $14 \%$ is still adequate for identifying polluted sites. While $w(\mathrm{Hg})$ in samples 1 ( $\mathrm{km} 57.4), 2$

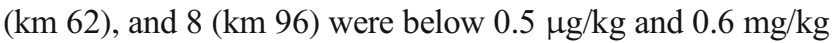
for $\mathrm{MMHg}$ and total $\mathrm{Hg}$, respectively, and thereby close to the postulated natural background, samples $3(\mathrm{~km} 73.86)$ to $7(\mathrm{~km}$ 88.91) show strongly elevated levels above $20 \mu \mathrm{g} / \mathrm{kg}$ and 9 $\mathrm{mg} / \mathrm{kg}$, respectively. This increase in between sampling sites 2 $(\mathrm{km} 62)$ and $3(\mathrm{~km} \mathrm{73.86)}$ corresponds most probably to the former location of a chemical plant that produced mercury-

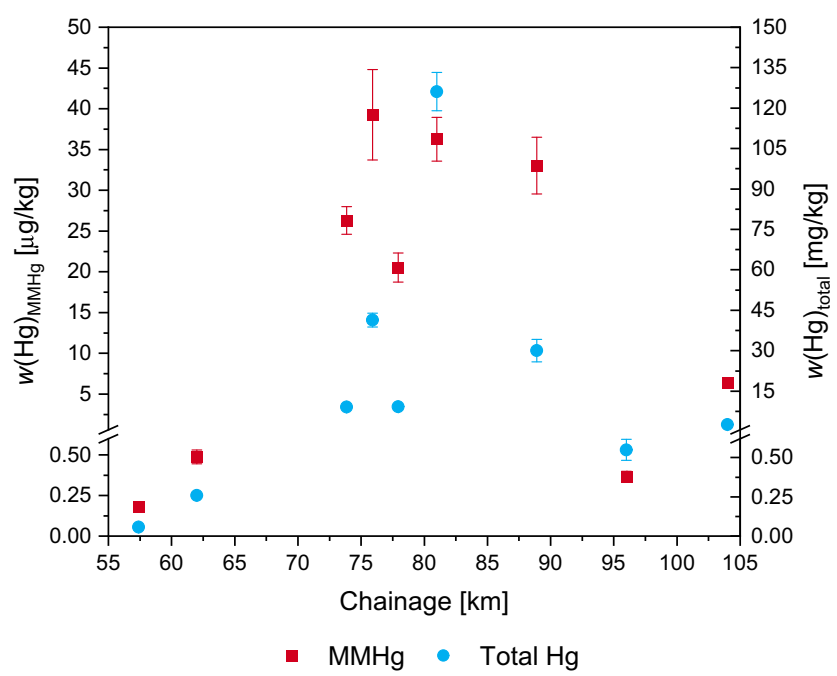

Fig. 4 Monomethylmercury ( $\mathrm{MMHg}), w(\mathrm{Hg})_{\mathrm{MMHg}}$, and total mercury, $w(\mathrm{Hg})_{\text {total }}$, mass fractions of sediment samples taken from Finow Canal. Note the different units for $\mathrm{MMHg} \mu \mathrm{g} / \mathrm{kg}$ and for total $\mathrm{Hg} \mathrm{mg} / \mathrm{kg}$. All mass fractions are based on dry weight of the $<250 \mu \mathrm{m}$ grain size fraction. Error bars represent expanded uncertainty $U(k=2)$ of $n=3$ sample replicates and are partially smaller than the symbol size. The exact position of the last two sampling sites was estimated based seed dressings and to the results of total $\mathrm{Hg}$ analysis in previous studies [28]. Interestingly, $w(\mathrm{Hg})_{\mathrm{MMHg}}$ is nearly constant over the course of Finow Canal with a drop after the confluence with the Oder-Havel Canal (sample 8, km 96), but even approximately $16 \mathrm{~km}$ downstream of the confluence, a $w(\mathrm{Hg})_{\mathrm{MMHg}}$ around one order of magnitude above natural background was found (sample 9, $\mathrm{km} \mathrm{104).} \mathrm{For} w(\mathrm{Hg})_{\text {total }}$, the maximum value of more than $100 \mathrm{mg} / \mathrm{kg}$ agrees with previous studies; however, back then the maximum was observed at

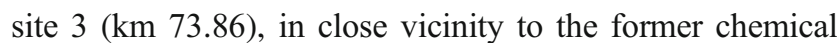
plant, with decreasing values in downstream direction. This could indicate a substantial downstream transport of contaminated sediment particles in recent years. In this context, it has to be noted that prior to a state horticultural show in 2002 , sediment from the area downstream of the former chemical plant was removed by dredging possibly explaining lower $w(\mathrm{Hg})_{\text {total }}$ at site $3(\mathrm{~km} \mathrm{73.86).} \mathrm{Also,} \mathrm{for} \mathrm{total} \mathrm{Hg}$, a drop after the confluence of both canals can be seen.

The $w(\mathrm{Hg})$ of MMHg and total $\mathrm{Hg}$ in samples $5(\mathrm{~km} 77.94)$ and $8(\mathrm{~km} \mathrm{96)} \mathrm{might} \mathrm{be} \mathrm{lower} \mathrm{than} \mathrm{at} \mathrm{neighboring} \mathrm{sites}(\mathrm{km}$ 75.9 and 80.99 , and $\mathrm{km} \mathrm{104}$, respectively) because here the sampling could only be done in small bays that were characterized by very low streaming and considerably less amount of fine-grain sediment than observed at the other sampling sites. Therefore, suspended contaminated sediment transported with the streaming is less likely to be deposited there. However, for a detailed investigation, a representative sampling regarding area and depth would have to be conducted.

The soil sample W, taken at the level of $\mathrm{km} \mathrm{79.5,} \mathrm{fits} \mathrm{in}$ with the overall trend of $\mathrm{MMHg}$ and total $\mathrm{Hg}$ contamination, with mass fractions of $(41 \pm 4) \mu \mathrm{g} / \mathrm{kg}$ and $(117 \pm 3) \mathrm{mg} / \mathrm{kg}$, respectively. This is rather surprising because no further $\mathrm{Hg} /$ MMHg deposition could have taken place since Finow Canal sediment was placed there for the last time around 40 years ago. Apparently, the topsoil is still heavily contaminated, and no considerable changes have occurred. Of course, it has to be said that this statement is based on only one sample from one location, and $w(\mathrm{Hg})_{\text {total }}$ and $w(\mathrm{Hg})_{\mathrm{MMHg}}$ may vary considerably in the whole washing bed due to variations in the soil conditions. Because this is not the only washing bed where sediment from Finow Canal has been deposited in the past, it is to be expected that these washing beds contaminated with legacy $\mathrm{Hg}$ have been and will be contributing largely to atmospheric $\mathrm{Hg}^{0}$ emissions, as soils have been described as a source for $\mathrm{Hg}^{0}$ [22].

The chromatogram of the soil sample (Fig. 5) shows the $\mathrm{Hg}$ speciation which was similar for all samples. The four species that could be identified by their retention time were elemental $\mathrm{Hg}\left(\mathrm{Hg}^{0}\right), \mathrm{MMHg}$, monoethyl-Hg (EtHg), and inorganic $\mathrm{Hg}$ $\left(\mathrm{Hg}^{2+}\right)$, detected as $\mathrm{Hg}^{0}$, methylpropyl-Hg, ethylpropyl-Hg, and dipropyl-Hg, respectively. Several small peaks could be observed on the tailing of $\mathrm{Hg}^{2+}$, but they could not be identified and are probably artifacts produced during derivatization. 


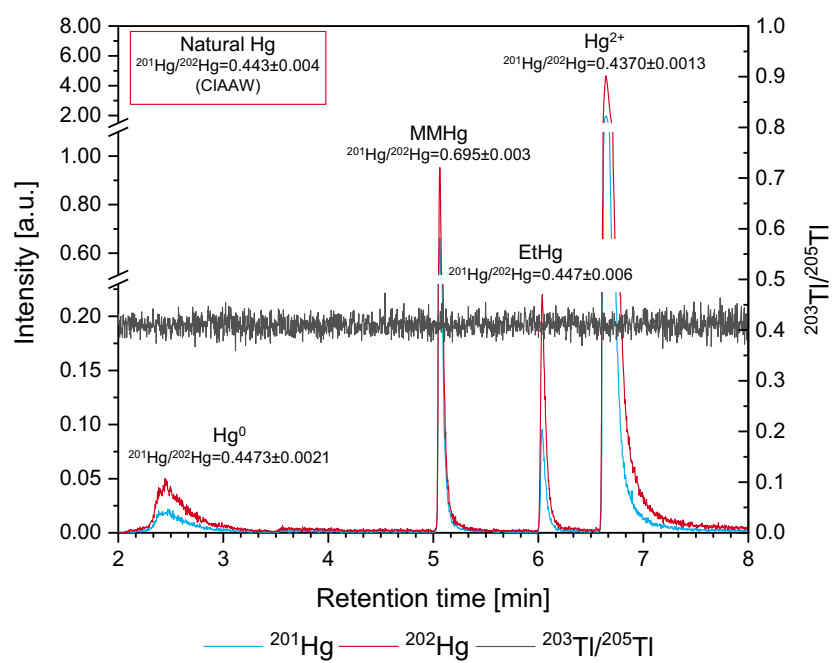

Fig. 5 Exemplary Hg speciation results via GC/ICP-ToF-MS of the soil sample (sample W) spiked with ${ }^{201} \mathrm{Hg}$-enriched $\mathrm{MMHg}$. Annotated ${ }^{201} \mathrm{Hg} /{ }^{202} \mathrm{Hg}$ isotope ratios and uncertainties were determined from $m=$ 3 measurements, and the natural isotope ratio was calculated from isotopic abundances and corresponding uncertainties taken from CIAAW. The ${ }^{201} \mathrm{Hg} /{ }^{202} \mathrm{Hg}$ of all species but MMHg are similar to the natural isotope ratio indicating that no species transformation takes place during sample preparation and analysis

It was shown in previous works that $\mathrm{Hg}^{0}$ is produced by reduction of analytes during sample preparation and/or analysis [44], whereas the amount of $\mathrm{Hg}^{0}$ present in the sample is lost during freeze-drying. Since it is described as rather unstable [24], EtHg most probably originates from the sample and is not an artifact, but the amount of EtHg indicated by the peak size seems to be surprisingly high. Unfortunately, due to the noted instability, quantification of EtHg is difficult, which is also highlighted by the lack of appropriate reference materials.

To investigate and exclude potential species transformation, the sample was spiked with ${ }^{201} \mathrm{Hg}$-enriched MMHg. Comparing the ${ }^{201} \mathrm{Hg}{ }^{202} \mathrm{Hg}$ of all species with the natural isotope ratio, it can be seen that all species but MMHg show an isotope ratio similar to the natural one. This indicates that no significant demethylation or reduction of MMHg takes place during sample preparation and analysis. Otherwise, the ${ }^{201} \mathrm{Hg} /{ }^{202} \mathrm{Hg}$ would have been shifted to values higher than natural.

The amount of substance fraction of $\mathrm{MMHg} / \mathrm{total} \mathrm{Hg}$ of all samples was between 0.029 and $0.32 \%$ corresponding to the proposed natural fraction of $0.1-1 \%$ [23]. No trends were observed between samples with supposedly natural $w(\mathrm{Hg})_{\text {total }}$ and $w(\mathrm{Hg})_{\mathrm{MMHg}}$ (samples 1 and 2) and samples affected by industrial contamination.

\section{Conclusions}

The performance of ICP-ToF-MS for SSID GC/ICP-MS analysis of MMHg was compared with ICP-Q-MS and ICP-SF-MS.
As opposed to the use in continuous liquid introduction, no improvement of isotope ratio precision was observed by using the ToF mass analyzer for transient signals when investigating only a limited number of isotopes. However, the (quasi-) simultaneous detection of the whole mass spectrum will probably lead to much better results of ICP-ToF-MS compared to the other singlecollector ICP-MS instruments, when more than one isotope system is used. This could be investigated further, e.g., by additionally analyzing organotin and organolead species, which can also be derivatized using aqueous phase alkylation to be accessible for GC speciation $[13,14]$.

Furthermore, the SSID GC/ICP-ToF-MS method was applied for the analysis of MMHg in sediments of Finow Canal, which is a heavily industrially polluted canal in Northern Germany. The high $w(\mathrm{Hg})_{\mathrm{MMHg}}$ determined in the samples show that natural (bio-)methylation of $\mathrm{Hg}$ is not hindered by the partially extremely high $\mathrm{Hg}$ concentration in the sediment. The analysis of one topsoil sample from a washing bed where contaminated sediment had been deposited around 40 years ago shows the same high values of both, $w(\mathrm{Hg})_{\text {total }}$ and $w(\mathrm{Hg})_{\mathrm{MmHg}}$. This means that Finow Canal sediments will act as a source for MMHg in this ecosystem for long time, whereas the sediment removed from the canal and deposited on washing beds contributes to atmospheric $\mathrm{Hg}^{0}$ emissions. It might be interesting to analyze also other environmental compartments (water, fish, plants) of this region to assess the overall status of $\mathrm{MMHg}$ distribution. Also, further investigation on the occurrence of EtHg could be interesting to see if it is produced within the sediment/soil or if it was released from the chemical plant because EtHg has been used as a component of seed dressings.

Supplementary Information The online version contains supplementary material available at https://doi.org/10.1007/s00216-021-03497-z.

Acknowledgements The Oder-Havel Office for Waterways and Shipping (WSA Oder-Havel) located in Eberswalde, Germany, is gratefully acknowledged for providing access to the sampling sites at Finow Canal. The authors want to thank Ali Usama for assistance during the sampling and sample preparation.

Availability of data and material Instrumental parameters, the sample preparation procedure for SSID GC/ICP-MS quantification of MMHg, and results of all samples and reference materials can be found in the ESM.

Code availability Not applicable.

Funding Open Access funding enabled and organized by Projekt DEAL. The German Research Foundation (DFG - Deutsche Forschungsgemeinschaft; reference number: ME 3685/3-1, project number: 321800101 ) is gratefully acknowledged for funding. 


\section{Declarations}

Conflict of interest The authors declare no competing interests.

Open Access This article is licensed under a Creative Commons Attribution 4.0 International License, which permits use, sharing, adaptation, distribution and reproduction in any medium or format, as long as you give appropriate credit to the original author(s) and the source, provide a link to the Creative Commons licence, and indicate if changes were made. The images or other third party material in this article are included in the article's Creative Commons licence, unless indicated otherwise in a credit line to the material. If material is not included in the article's Creative Commons licence and your intended use is not permitted by statutory regulation or exceeds the permitted use, you will need to obtain permission directly from the copyright holder. To view a copy of this licence, visit http://creativecommons.org/licenses/by/4.0/.

\section{References}

1. Vogl J, Pritzkow W. Isotope dilution mass spectrometry - a primary method of measurement and its role for RM certification. MAPAN. 2010;25:135-64. https://doi.org/10.1007/s12647-0100017-7.

2. Vogl J. Characterisation of reference materials by isotope dilution mass spectrometry. J Anal At Spectrom. 2007;22:475-92. https:// doi.org/10.1039/b614612k.

3. Ohata M, Hagino H. Examination on simultaneous multi-element isotope ratio measurement by inductively coupled plasma time of flight mass spectrometry. Int J Mass Spectrom. 2018;430:31-6. https://doi.org/10.1016/j.ijms.2018.03.003.

4. Hendriks L, Gundlach-Graham A, Hattendorf B, Günther D. Characterization of a new ICP-TOFMS instrument with continuous and discrete introduction of solutions. J Anal At Spectrom. 2017;32:548-61. https://doi.org/10.1039/c6ja00400h.

5. Vanhaecke F, Moens L, Dams R, Allen L, Georgitis S. Evaluation of the isotope ratio performance of an axial time-of-flight ICP mass spectrometer. Anal Chem. 1999;71:3297-303. https://doi.org/10. 1021/ac990016b.

6. Rodriguez-Gonzalez P, Epov VN, Pecheyran C, Amouroux D, Donard OF. Species-specific stable isotope analysis by the hyphenation of chromatographic techniques with MC-ICPMS. Mass Spectrom Rev. 2012;31:504-21. https://doi.org/10.1002/mas. 20352.

7. Szpunar J, McSheehy S, Połeć K, Vacchina V, Mounicou S, Rodriguez I, et al. Gas and liquid chromatography with inductively coupled plasma mass spectrometry detection for environmental speciation analysis - advances and limitations. Spectrochim Acta Part B. 2000;55:779-93. https://doi.org/10.1016/s05848547(00)00210-x.

8. Moldovan M, Krupp EM, Holliday AE, Donard OFX. High resolution sector field ICP-MS and multicollector ICP-MS as tools for trace metal speciation in environmental studies: a review. J Anal At Spectrom. 2004;19:815-22. https://doi.org/10.1039/b403128h.

9. Jagtap R, Maher W. Measurement of mercury species in sediments and soils by HPLC-ICPMS. Microchem J. 2015;121:65-98. https://doi.org/10.1016/j.microc.2015.01.010.

10. Leermakers M, Baeyens W, Quevauviller P, Horvat M. Mercury in environmental samples: speciation, artifacts and validation. TrAC Trends Anal Chem. 2005;24:383-93. https://doi.org/10.1016/j.trac. 2004.01.001.

11. Avramescu ML, Zhu J, Yumvihoze E, Hintelmann H, Fortin D, Lean DR. Simplified sample preparation procedure for measuring isotope-enriched methylmercury by gas chromatography and inductively coupled plasma mass spectrometry. Environ Toxicol Chem. 2010;29:1256-62. https://doi.org/10.1002/etc.158.

12. Ma X, Yin Y-G, Shi J-B, Liu J-F, Jiang G-B. Species-specific isotope dilution-GC-ICP-MS for accurate and precise measurement of methylmercury in water, sediments and biological tissues. Anal Methods. 2014;6:164-9. https://doi.org/10.1039/c3ay41625a.

13. Teran-Baamonde J, Bouchet S, Tessier E, Amouroux D. Development of a large volume injection method using a programmed temperature vaporization injector - gas chromatography hyphenated to ICP-MS for the simultaneous determination of mercury, tin and lead species at ultra-trace levels in natural waters. $\mathrm{J}$ Chromatogr A. 2018;1547:77-85. https://doi.org/10.1016/j. chroma.2018.02.056

14. Poperechna N, Heumann KG. Simultaneous multi-species determination of trimethyllead, monomethylmercury and three butyltin compounds by species-specific isotope dilution GC-ICP-MS in biological samples. Anal Bioanal Chem. 2005;383:153-9. https://doi. org/10.1007/s00216-005-0036-3.

15. Brombach CC, Manorut P, Kolambage-Dona PPP, Ezzeldin MF, Chen B, Corns WT, et al. Methylmercury varies more than one order of magnitude in commercial European rice. Food Chem. 2017;214:360-5. https://doi.org/10.1016/j.foodchem.2016.07.064.

16. Heilmann J, Heumann KG. Development of a species-specific isotope dilution GC-ICP-MS method for the determination of thiophene derivates in petroleum products. Anal Bioanal Chem. 2008;390:643-53. https://doi.org/10.1007/s00216-007-1574-7.

17. Pinel-Raffaitin P, Rodríguez-González P, Ponthieu M, Amouroux D, Le Hecho I, Mazeas L, et al. Determination of alkylated tin compounds in landfill leachates using isotopically enriched tin species with GC-ICP-MS detection. J Anal At Spectrom. 2007;22: 258-66. https://doi.org/10.1039/b614780a.

18. Haas K, Feldmann J, Wennrich R, Stark HJ. Species-specific isotope-ratio measurements of volatile tin and antimony compounds using capillary GC-ICP-time-of-flight MS. Fresenius J Anal Chem. 2001;370:587-96. https://doi.org/10.1007/s002160100797.

19. Wehmeier S, Ellam R, Feldmann J. Isotope ratio determination of antimony from the transient signal of trimethylstibine by GC-MCICP-MS and GC-ICP-TOF-MS. J Anal At Spectrom. 2003;18: 1001-7. https://doi.org/10.1039/b302242k.

20. Beckers F, Rinklebe J. Cycling of mercury in the environment: sources, fate, and human health implications: a review. Crit Rev Environ Sci Technol. 2017;47:693-794. https://doi.org/10.1080/ 10643389.2017.1326277.

21. Du H, Ma M, Igarashi Y, Wang D. Biotic and abiotic degradation of methylmercury in aquatic ecosystems: a review. Bull Environ Contam Toxicol. 2019;102:605-11. https://doi.org/10.1007/ s00128-018-2530-2.

22. Gworek B, Dmuchowski W, Baczewska-Dąbrowska AH. Mercury in the terrestrial environment: a review. Environ Sci Eur. 2020;32: 128. https://doi.org/10.1186/s12302-020-00401-x.

23. Hintelmann H. Comparison of different extraction techniques used for methylmercury analysis with respect to accidental formation of methylmercury during sample preparation. Chemosphere. 1999;39: 1093-105. https://doi.org/10.1016/s0045-6535(99)00180-0.

24. Hellmann C, Costa RD, Schmitz OJ. How to deal with mercury in sediments? A critical review about used methods for the speciation of mercury in sediments. Chromatographia. 2019;82:125-41. https://doi.org/10.1007/s10337-018-3625-y.

25. Jones TA, Chumchal MM, Drenner RW, Timmins GN, Nowlin WH. Bottom-up nutrient and top-down fish impacts on insectmediated mercury flux from aquatic ecosystems. Environ Toxicol Chem. 2013;32:612-8. https://doi.org/10.1002/etc.2079.

26. Cristol DA, Brasso RL, Condon AM, Fovargue RE, Friedman SL, Hallinger KK, et al. The movement of aquatic mercury through 
terrestrial food webs. Science. 2008;320:335. https://doi.org/10. 1126/science.1154082.

27. Feiler U, Hoss S, AhlfW, Gilberg D, Hammers-Wirtz M, Hollert H, et al. Sediment contact tests as a tool for the assessment of sediment quality in German waters. Environ Toxicol Chem. 2013;32:14455. https://doi.org/10.1002/etc.2024.

28. Pelzer J. The sediment quality in the Finow Canal. In: Sediment assessment in European river basins; April 12-14, 1999; Berlin. Koblenz: German Federal Institute of Hydrology; 1999. p. 73-5.

29. Jansky H-J, Neumann V, Pelzer J. Investigations into the processing of dredged material from Germany's oldest canal. In: Sarsby RW, Meggyes T, editors. GREEN 3: the 3rd International Symposium on Geotechnics Related to the European Environment; June 21-23, 2000; Berlin. London: Thomas Telford Ltd.; 2000. p. 203-10. https://doi.org/10.1680/teonratc.30046. 0032.

30. Driscoll CT, Mason RP, Chan HM, Jacob DJ, Pirrone N. Mercury as a global pollutant: sources, pathways, and effects. Environ Sci Technol. 2013;47:4967-83. https://doi.org/10.1021/es305071v.

31. Muhaya BBM, Leermakers M, Baeyens W. Influence of sediment preservation on total mercury and methylmercury analyses. Water Air Soil Pollut. 1998;107:277-88. https://doi.org/10.1023/a: 1019886606856.

32. DIN EN 15934:2012-11, Sludge, treated biowaste, soil and waste calculation of dry matter fraction after determination of dry residue or water content

33. Carrasco L, Vassileva E. Determination of methylmercury in marine sediment samples: method validation and occurrence data. Anal Chim Acta. 2015;853:167-78. https://doi.org/10.1016/j.aca. 2014.10.026.

34. Epov VN, Berail S, Jimenez-Moreno M, Perrot V, Pecheyran C, Amouroux D, et al. Approach to measure isotopic ratios in species using multicollector-ICPMS coupled with chromatography. Anal Chem. 2010;82:5652-62. https://doi.org/10.1021/ac100648f.

35. Epov VN, Rodriguez-Gonzalez P, Sonke JE, Tessier E, Amouroux D, Bourgoin LM, et al. Simultaneous determination of species- specific isotopic composition of $\mathrm{Hg}$ by gas chromatography coupled to multicollector ICPMS. Anal Chem. 2008;80:3530-8. https://doi.org/10.1021/ac800384b.

36. Faßbender S, Rodiouchkina K, Vanhaecke F, Meermann B. Method development for on-line species-specific sulfur isotopic analysis by means of capillary electrophoresis/multicollector ICPmass spectrometry. Anal Bioanal Chem. 2020;412:5637-46. https://doi.org/10.1007/s00216-020-02781-8.

37. Meija J, Coplen TB, Berglund M, Brand WA, De Bièvre P, Gröning M, et al. Isotopic compositions of the elements 2013 (IUPAC Technical Report). Pure Appl Chem. 2016;88:293-306. https://doi.org/10.1515/pac-2015-0503.

38. CIAAW. Current atomic masses. 2016. https://www.ciaaw.org/ atomic-masses.htm. Accessed January 2021.

39. CIAAW. Isotopic compositions of the elements. 2019. https:// www.ciaaw.org/isotopic-abundances.htm. Accessed January 2021.

40. Kragten J. Tutorial review. Calculating standard deviations and confidence intervals with a universally applicable spreadsheet technique. Analyst. 1994;119:2161-6. https://doi.org/10.1039/ an9941902161.

41. DIN EN ISO/IEC 17043:2010-05, Conformity assessment - general requirements for proficiency testing.

42. Thomas R. Practical guide to ICP-MS. New York, Basel: Marcel Dekker, Inc.; 2004.

43. TOFWERK AG. TOFWERK icpTOF specifications. 2019. https:// www.tofwerk.com/wp-content/uploads/icpTOF-Specifications2020-1-10.pdf. Accessed 21 May 2021.

44. Lambertsson L, Lundberg E, Nilsson M, Frech W. Applications of enriched stable isotope tracers in combination with isotope dilution GC-ICP-MS to study mercury species transformation in sea sediments during in situ ethylation and determination. J Anal At Spectrom. 2001;16:1296-301. https://doi.org/10.1039/b106878b.

Publisher's note Springer Nature remains neutral with regard to jurisdictional claims in published maps and institutional affiliations. 